\title{
EFICACIA EXPERIMENTAL DE ANTICUERPOS IgY PRODUCIDOS EN HUEVOS, CONTRA EL VENENO DE LA SERPIENTE PERUANA Bothrops atrox
}

\author{
Julio C. Mendoza ${ }^{1, a}$, Dan Vivas ${ }^{1, a}$, Edith Rodríguez ${ }^{1, b}$, Rosio Inga ${ }^{1, b}$, Gustavo Sandoval ${ }^{1, b}$, \\ Fanny Lazo ${ }^{1, c}$, Armando Yarlequé ${ }^{1, d}$
}

\begin{abstract}
RESUMEN
Objetivos. Desarrollar un protocolo de inmunización para producir inmunoglobulinas $\lg Y$ de origen aviar contra el veneno de la serpiente peruana Bothrops atrox y evaluar la capacidad neutralizante. Materiales y métodos. Se inmunizaron seis gallinas de postura de la raza hy line brown con $500 \mu \mathrm{g} / \mathrm{dosis}$ de veneno de $B$. atrox en un periodo de dos meses. Cada semana, los huevos fueron colectados para el aislamiento de inmunoglobulinas lgY a partir de la yema, usando dos pasos consecutivos con ácido caprílico y sulfato de amonio. La detección de anticuerpos se realizó por inmunodifusión doble mientras que el título y reactividad cruzada se determinaron por las técnicas de ELISA y Western blot. El cálculo de $\mathrm{DL}_{50}$ y de la $\mathrm{DE}_{50}$ del antiveneno lgY producido se realizó utilizando el método de Probits. Resultados. La masa de anticuerpos aislados fue de $8,5 \pm 1,35 \mathrm{mg}$ de $\mathrm{lgY} / \mathrm{mL}$ de yema. Asimismo, la $\mathrm{DE}_{50}$ del antiveneno aviar fue calculada en 575 $\mu \mathrm{L}$ de antiveneno/mg de veneno. Adicionalmente, los ensayos de reactividad cruzada mostraron que el veneno de $B$. atrox comparte mas epítopes comunes con el veneno de $B$. brazili (47\%) que con otros veneno del mismo género, en tanto que los venenos de Lachesis muta (19\%) y Crotalus durissus (12\%) mostraron una baja reactividad cruzada. Conclusiones. Se ha obtenido IgY purificada contra el veneno de $B$. atrox con capacidad neutralizante y se ha demostrado su utilidad como herramienta inmunoanalítica para evaluar la reactividad cruzada con venenos de otras especies.
\end{abstract}

Palabras clave: Venenos de serpiente; Antivenenos; Neutralización; Bothrops atrox (fuente: DeCS BIREME).

\section{EXPERIMENTAL EFFICACY OF IgY ANTIBODIES PRODUCED IN EGGS AGAINST THE VENOM OF THE PERUVIAN SNAKE Bothrops atrox}

\begin{abstract}
Objectives. To develop an immunization protocol in order to produce avian IgY immunoglobulins against Bothrops atrox Peruvian snake venom and to evaluate its neutralizing capacity. Materials and methods. Six Hy Line Brown hens were immunized each two weeks using $500 \mu \mathrm{g} /$ doses of $B$. atrox venom in a period of two months. Each week, eggs were collected for $\lg Y$ isolation from yolk using two consecutive steps with caprilic acid and ammonium sulfate. Detection of $\lg Y$ anti-B. atrox were performed by double immunodiffusion, whereas title and cross-reactivity were analyzed using ELISA and Western Blot technics, respectively. Furthermore, letal dose $\left(\mathrm{DL}_{50}\right)$ and Medium Effective Dose $\left(\mathrm{DE}_{50}\right)$ were obtained by Probit analysis. Results. As a result of this protocol, chicken IgY's were obtained in a concentration of $8,5 \pm 1,35$ $\mathrm{mg} /$ yolk $\mathrm{mL}$. $\mathrm{DE}_{50}$ from avian antivenom was $575 \mu \mathrm{L} / \mathrm{venom} \mathrm{mg}$. Cross-reactivity studies showed Bothrops atrox venom share more commom epitopes with Bothrops brazili (47\%) than others Bothrops venoms showing Lachesis muta $(19 \%)$ and Crotalus durissus (12\%) venoms a low crossing reactivity, instead. Conclusions. Using this procedure, we could purify chicken IgY with a neutralizant capacity of $B$. atrox venom which is comparable to the antivenom of equine origin and demonstrate its capacity as a immunoanalitical tool to evaluate the cross reactivity with others peruvian snakes.
\end{abstract}

Key words: Snake venoms; Antivenins; Neutralization; Bothrops atrox (source: MeSH NLM).

\section{INTRODUCCIÓN}

En el Perú, la "jergón" Bothrops atrox es la serpiente responsable de la mayoría de accidentes en la selva, con un 88 a $92 \%$ de todos los casos descritos (1) su mordedura desencadena un cuadro clínico muy complejo con efectos locales y sistémicos que se manifiestan mientras no se suministre tratamiento específico.

Los efectos letales del veneno y el desequilibrio hemostático producidos, son neutralizados y restablecidos respectivamente por el antiveneno producido en caballos, el cual contiene inmunoglobulinas G. Existe, sin

\footnotetext{
1 Laboratorio de Biología Molecular, Facultad de Ciencias Biológicas, Universidad Nacional Mayor de San Marcos. Lima, Perú.

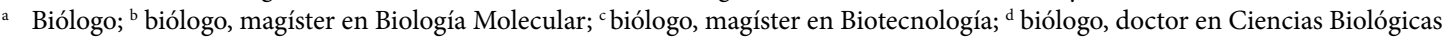

Recibido: 12-12-11 Aprobado: 22-02-12 
embargo, el riesgo latente de que el paciente sufra reacciones anafilácticas $o$ anafiloctoides debido al inmunosuero ${ }^{(2)}$.

Desde hace dos décadas se iniciaron los trabajos para poner en marcha la tecnología inmunoglobulina Y (IgY) basada en la concentración de dichos anticuerpos en la yema de huevo de gallinas inmunizadas. Las IgY no se unen a receptores de la región Fc de las cadenas pesadas en las inmunoglobulinas, no muestran reacciones cruzadas con factores reumatoideos que ocasionan falsos positivos en ensayos de ELISA y, sobre todo, no activan el sistema de complemento, además de su menor costo de producción y alto rendimiento sin usarse métodos invasivos para su obtención ${ }^{(3)}$.

La preparación de antivenenos basada en anticuerpos IgY extraídos de yema de huevo de gallinas se inició en la década del 1990 con la publicación de los trabajos de Thalley y Carroll (4), quienes inmunizaron gallinas de postura con veneno de la cascabel diamante del oeste de EE. UU. (Crotalus atrox) y del escorpión amarillo (Leiurus quinquestriatus hebraeus). Sus resultados mostraron que los antivenenos aviares purificados por afinidad a partir de yema de huevo poseen capacidad protectora del $100 \%$ contra el envenenamiento experimental y son útiles en la detección de reactividad cruzada con otros venenos sobre membranas de nitrocelulosa sugiriendo que dicha fuente de anticuerpos es una buena alternativa al uso de anticuerpos de origen mamífero. De esta manera se han desarrollado antivenenos aviares contra los venenos de las serpientes de los géneros Bothrops y Crotalus ${ }^{(5)}$, así como también serpientes de importancia en la India como Daboia russelii ${ }^{(6)}$, Echis carinatus ${ }^{(7)}$, Naja naja y Bungarus caeruleus ${ }^{(8)}$, de los géneros Bitis y Naja ${ }^{(9)}$ y otros vipéridos ${ }^{(10)}$. Es importante señalar el uso de estos anticuerpos IgY en el desarrollo de herramientas inmunoanalíticas para la detección de veneno de Naja naja naja en muestras de origen forense ${ }^{(11)}$.

Es por ello que se ha desarrollado la presente investigación que aporta los primeros datos en el país sobre la efectividad del antiveneno basado en tecnología IgY, se ha determinando su dosis efectiva $\left(D_{50}\right)$ y el uso de anticuerpos aviares como herramienta inmunoanalítica en estudios de reactividad cruzada con venenos peruanos.

\section{MATERIALES Y MÉTODOS}

Se realizó una investigación experimental de neutralización de veneno de Bothrops. Los venenos liofilizados de serpientes peruanas (Bothrops atrox 7 ,
Bothrops barnetti 4, Bothrops brazili 6, Bothrops pictus 2, Lachesis muta 2 y Crotalus durisus 2) proceden de ejemplares mantenidos en cautiverio en el serpentario "Oswaldo Meneses" del Museo de Historia Natural de la Universidad Nacional Mayor de San Marcos. Cada veneno fue pesado y diluido en solución salina o amortiguador Tris- $\mathrm{HCl} 0,05 \mathrm{M}, \mathrm{pH} 7,4$ a una concentración de $30 \mathrm{mg} / \mathrm{mL}$ y mantenido a $-20^{\circ} \mathrm{C}$.

Para la experimentación, se utilizaron seis gallinas de postura de raza hy line brown de veinte semanas de edad y $1,5 \mathrm{~kg}$ de peso, mantenidas bajo condiciones de alimento y peso controlados. Los huevos obtenidos cada semana en la postura de las gallinas fueron rotulados y mantenidos a $4^{\circ} \mathrm{C}$ hasta su procesamiento.

\section{ENSAYOS DE LETALIDAD}

Se utilizaron ratones albinos machos (cepa Balb-C) de 18 a $20 \mathrm{~g}$, los cuales fueron inoculados por vía intraperitoneal con distintas diluciones de veneno de $B$. atrox, se usó solución salina como control. Cada grupo de cinco ratones fue observado durante 48 horas y se fue anotando el número de muertes. El cálculo de la dosis letal media $\left(\mathrm{DL}_{50}\right)$ se realizó utilizando el método de Probits ${ }^{(12)}$.

Se realizó el análisis electroforético en PAGE-SDS (Poliacrylamide gel Electrophoresis), siguiendo la

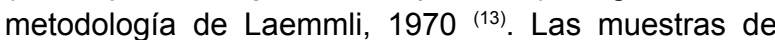
veneno y antiveneno fueron colocadas en los geles de poliacrilamida (12 y $10 \%$ respectivamente).

La cuantificación de proteínas se realizó midiendo la absorbancia de luz UV a $280 \mathrm{~nm}$ en un espectrofotómetro UV visible Shimadzu (Warburg y Christian, 1941) y además por el método de Lowry et al. (1951) (15) empleando albúmina sérica bovina como proteína estándar.

\section{PROTOCOLO DE INMUNIZACIÓN}

Se inocularon dosis de $500 \mu \mathrm{g}$ de veneno emulsificado con adyuvante completo de Freund (ACF) en un volumen de $1 \mathrm{~mL}$ por vía intramuscular (i.m.) en cuatro puntos en la zona pectoral de cada gallina. El primer refuerzo se dio luego de dos semanas y el segundo refuerzo luego de cinco semanas de iniciado el protocolo, ambos con adyuvante incompleto de Freund (AIF). Los huevos colectados fueron almacenados a $4^{\circ} \mathrm{C}$ y el suero de las sangrías parciales a $-20^{\circ} \mathrm{C}$. Luego de dos meses de haber culminado con el protocolo de inmunización, se inoculó un refuerzo con el mismo antígeno en AIF para evaluar la cinética de aparición de anticuerpos posrefuerzo. 


\section{AISLAMIENTO DEANTICUERPOS DE YEMA DE HUEVO}

Los anticuerpos $\lg Y$ fueron aislados según el método adaptado descrito por Mc Laren et al. ${ }^{(16)}$. Se separó la yema y se lavó con agua destilada, luego se secó con papel filtro para retirar restos de clara. Se diluyeron $10 \mathrm{~mL}$ de yema con dos volúmenes de PBS pH 7,4 y luego se ajustó el pH a 5 con ácido acético al $60 \%$. Se añadió acido caprílico ( $64 \mu \mathrm{L} / \mathrm{mL}$ de dilución) por goteo y en agitación vigorosa a una velocidad de $600 \mu \mathrm{L} / \mathrm{min}$. Se dejó en agitación durante dos horas a temperatura ambiente hasta que adquirió consistencia pastosa, se filtró y se llevó a pH 7 con Tris $1 \mathrm{M}$. Para eliminar proteínas contaminantes sensibles al congelamiento, las muestras fueron colocadas a $-10^{\circ} \mathrm{C}$ toda la noche, luego descongeladas a temperatura ambiente y centrifugadas a $2600 \mathrm{~g}$ por treinta minutos. El sobrenadante fue sometido a fraccionamiento con sulfato de amonio $(0,231 \mathrm{~g} / \mathrm{mL}$ de solución) bajo agitación suave y constante a $4{ }^{\circ} \mathrm{C}$ por una hora. Nuevamente se centrifugó (2600 g por $30 \mathrm{~min}$ ) y el pellet obtenido, con los anticuerpos aislados, fue resuspendido en $10 \mathrm{~mL}$ de PBS $\mathrm{pH}$ 7,4 y dializado contra el mismo.

\section{DETECCIÓN DE ANTICUERPOS POR INMUNODIFUSIÓN DOBLE}

Fue realizada según el método descrito por Ouchterlony y Nilsson (1978) ${ }^{(17)}$. La agarosa fue preparada con PBS $\mathrm{pH} 7,4$ y $\mathrm{NaCl} 1 \mathrm{M}$. Se emplearon los sueros de sangrías parciales y los extractos de lgY obtenidos semanalmente $(8,5 \pm 1,35 \mathrm{mg} / \mathrm{mL})$ a partir de yema de huevo, utilizando como controles positivo y negativo antiveneno botrópico producido en el Instituto Nacional de Salud (lote: 1000376) y solución salina, respectivamente.

\section{DETERMINACIÓN DEL TÍTULO DE ANTICUERPOS}

Para ello se emplearon placas de 96 pocillos las cuales fueron cubiertas con $100 \mu \mathrm{l} /$ pocillo de veneno de $B$. atrox $(0,5 \mu \mathrm{g} / \mathrm{mL})$ diluido en amortiguador de cubierta $\left(\mathrm{Na}_{2} \mathrm{CO}_{3}\right.$ $\left.0,015 \mathrm{M} ; \mathrm{NaHCO}_{3} 0,035 \mathrm{M} ; \mathrm{pH} 9,6\right)$ durante una noche a $4{ }^{\circ} \mathrm{C}$. Al día siguiente, luego de tres lavados sucesivos ( $\mathrm{NaCl} 0,15 \mathrm{M}$, Tween-20 0,1\%) se bloquearon las placas por una hora a $37^{\circ} \mathrm{C}$ (leche descremada $3 \%$, Tween-20 $0,1 \%$, PBS pH 7,4). Se aplicaron $100 \mu \mathrm{L} /$ pocillo de suero de gallina o extracto de yema de huevo diluidos seriadamente con factor 0,5 desde $1 / 800$ y se incubaron una hora a $37^{\circ} \mathrm{C}$. Luego de lavados sucesivos, se adicionó anti-IgY comercial (SIGMA Co.) producido en conejo, conjugado con fosfatasa alcalina ( $1 / 4000$ en amortiguador de bloqueo) y se incubó por una hora a $37^{\circ} \mathrm{C}$. Las placas fueron lavadas nuevamente y fue adicionado el sustrato p-nitrofenil fosfato (100 $\mu \mathrm{L} /$ pocillo). Después de $30 \mathrm{~min}$, la reacción fue detenida mediante la adición de $50 \mu \mathrm{L} /$ pocillo de $\mathrm{NaOH} 3 \mathrm{M}$ y las lecturas de absorbancia a $405 \mathrm{~nm}$ se registraron en un lector de placas Titertek Multiskan PLUS MKII. El título correspondió a la inversa de la dilución de extracto de yema que produjo el $50 \%$ de la máxima absorbancia registrada.

\section{PRUEBAS DE REACTIVIDAD CRUZADA CON OTROS VENENOS}

Se evaluó la reactividad cruzada con venenos del mismo género (B. barnetti, B. brazili, B. pictus) además de los venenos de $L$. muta y $C$. durissus mediante ensayos de ELISA (1/800 de IgY aislada) y Western blot con el suero inmune (1/1000) o anticuerpos IgY anti-B.atrox purificados por cromatografía de afinidad (1/400).

\section{ENSAYO DE NEUTRALIZACIÓN DE LA LETALIDAD}

Para realizar este ensayo, se preparó el antiveneno aviar a una concentración de $35 \mathrm{mg} / \mathrm{mL}$. Posteriormente, se hicieron mezclas en proporciones de $1 ; 0,5$ y $0,25 \mu \mathrm{L}$ antiveneno/mg veneno usando una dosis reto calculada de $3,34 \mathrm{DL}_{50}(200 \mu \mathrm{g}$ de veneno). Como control positivo y negativo se utilizaron las dosis reto y solución salina, respectivamente. Las mezclas fueron incubadas por una hora a $37^{\circ} \mathrm{C}$ y luego inoculadas vía intraperitoneal $(0,2 \mathrm{~mL})$ en grupos de cuatro ratones albinos machos de 18 a 20 g. Cada ratón fue observado por 48 h y se anotó el número de muertes. Posteriormente, se efectuó el análisis estadístico por el método computarizado de Probits ${ }^{(12)}$.

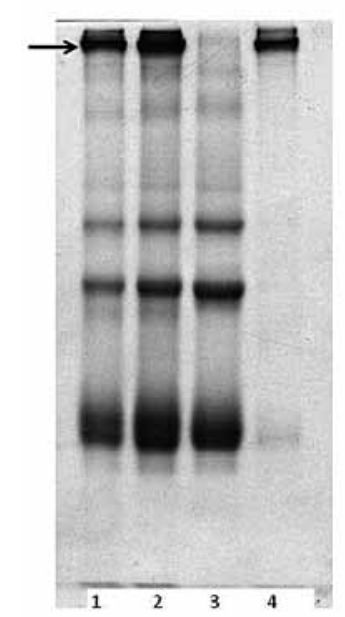

Figura 1. Análisis electroforético en gel de poliacrilamida con SDS (concentración del gel 10\%, condiciones no reductoras) del extracto acuoso durante el protocolo de aislamiento de anticuerpos $\lg Y$.

Carril 1: extracto luego del primer paso con ácido caprílico. Carril 2: extracto inicial a $\mathrm{pH} 7$ en el segundo paso con sulfato de amonio. Carril 3: sobrenadante obtenido luego del proceso de salting-out con sulfato de amonio. Carril 4: precipitado luego del proceso de salting-out con sulfato de amonio. La flecha indica la banda correspondiente a las inmunoglobulinas $\lg$ Y. 

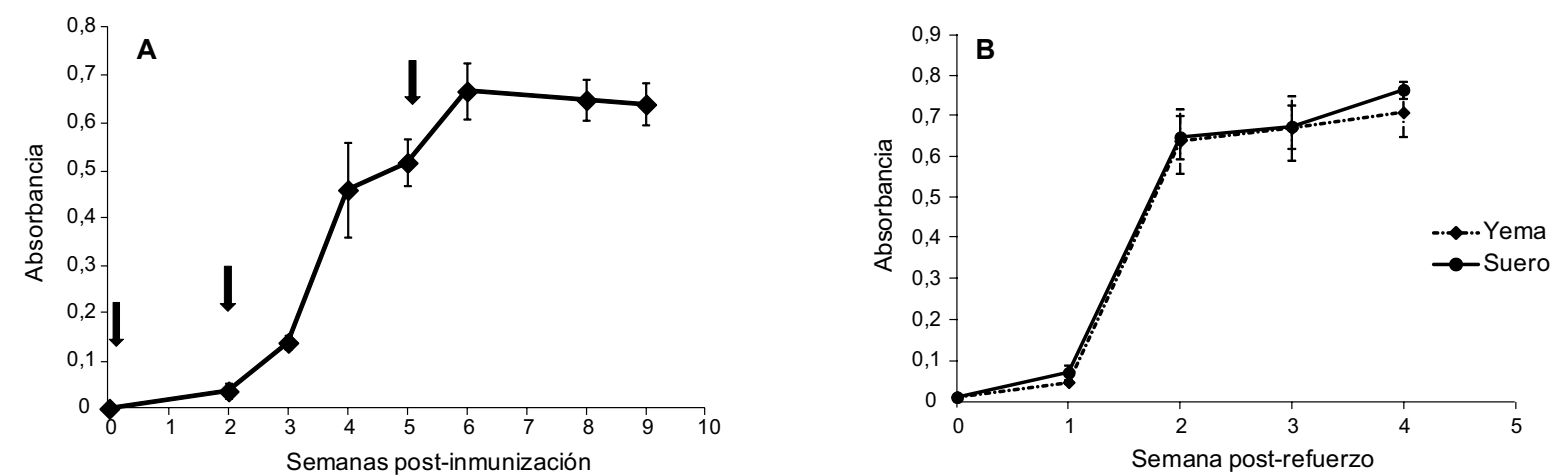

Figura 2. Aparición de anticuerpos contra veneno de Bothrops en gallinas durante la inoculación experimental.

(A) Curva de aparición de IgY anti-B. atrox en yema de huevo (dilución 1/800) durante el protocolo de inmunización. Las flechas indican la semana de inoculación de antígeno. (B) Curva de aparición de anticuerpos IgY-anti- $B$. atrox posrefuerzo de gallinas previamente sensibilizadas con el protocolo de trabajo. $(\bullet)$ valores encontrados en yema. $(\bullet)$ valores encontrados en suero.

\section{RESULTADOS}

\section{AISLAMIENTO DE IgY}

La metodología descrita proporcionó anticuerpos con escasos contaminantes (Figura 1). La banda principal corresponde a las inmunoglobulinas IgY. La concentración proteica de cada extracto obtenido fue de $8,5 \pm 1,35 \mathrm{mg} / \mathrm{mL}$ de yema, esto es $127,5 \mathrm{mg}$ por yema. Considerando que cada gallina puede poner como mínimo cinco huevos por semana, esto sería $2550 \mathrm{mg}$ de anticuerpos específicos por mes obtenido de una sola gallina.

\section{RESPUESTA INMUNOLÓGICA Y TÍTULO}

La Figura 2 muestra la cinética de aparición de anticuerpos durante el protocolo de inmunización, lográndose títulos altos desde la sexta semana. Por otro lado, la cinética de aparición de anticuerpos en suero y en yema posrefuerzo muestra la rápida respuesta a partir de la segunda semana debido a células $B$ de

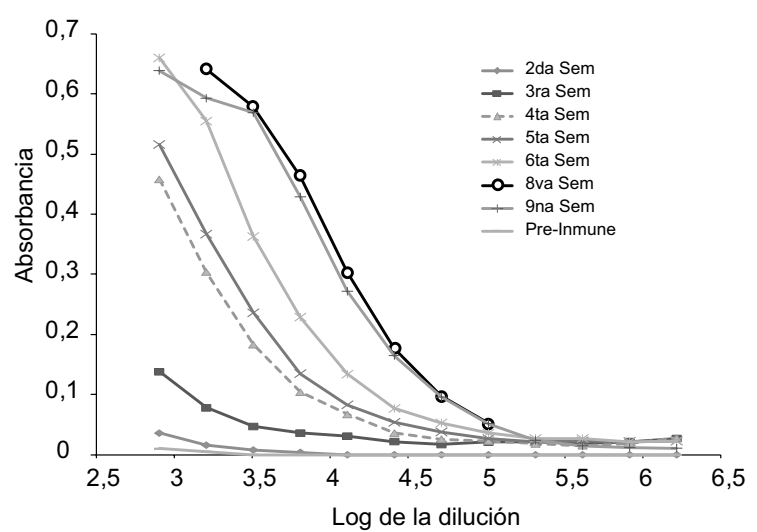

Figura 3. Perfil del título de anticuerpos de yema de huevo (IgY) anti-B. atrox por ELISA indirecto.

El título (12800) corresponde al antilogaritmo de la dilución de extracto de yema que produjo el $50 \%$ de la máxima absorbancia registrada utilizando $50 \mathrm{ng}$ de antígeno ligado a la placa. memoria (Figura 2). El título más alto obtenido fue de 12800 a la octava semana del protocolo (Figura 3), permaneciendo alta por cuatro semanas como mínimo.

\section{REACTIVIDAD CRUZADA}

Los porcentajes de reactividad cruzada encontrados cuando los anticuerpos anti- $B$. atrox fueron enfrentados con los venenos de $B$. barnetti, B. brazili, B. pictus, $C$. durissus y $L$. muta utilizando la técnica de ELISA fueron $37 ; 47 ; 41 ; 12$ y $19 \%$, respectivamente.

Cuando se enfrentaron las IgY anti B-atrox con los venenos de serpientes del género Bothrops, Lachesis y Crotalus sobre membranas de nitrocelulosa se obtuvieron bandas de reactividad cruzada más nítidas con las IgY purificadas que con el suero hiperinmune de gallina. El veneno de $B$. brazili presenta una banda principal muy marcada, responsable de la reactividad cruzada. En los venenos de Lachesis muta y Crotalus durissus se han reconocido bandas de bajo peso molecular cercanas a $14 \mathrm{kDa}$; en cambio, en el veneno de $B$. pictus solo se reconocen dos bandas de $\sim 20$ y $\sim 14 \mathrm{kDa}$ por los anticuerpos IgY-anti B.atrox. En contraste, el veneno de $B$. barnetti presenta varias bandas de distintos pesos reconocidas por las IgY.

\section{NEUTRALIZACIÓN DE LA LETALIDAD}

La dosis letal media $\left(\mathrm{DL}_{50}\right)$ calculada para el veneno de $B$. atrox fue de $3,33 \pm 0,5 \mu \mathrm{g} / \mathrm{g}$ ratón, cuyo valor fue utilizado para determinar la dosis reto cuando se inocularon $200 \mu \mathrm{g}$ de veneno/ratón $\left(3,34 \mathrm{DL}_{50}\right)$. El antiveneno aviar tuvo una dosis efectiva media $\left(\mathrm{DE}_{50}\right)$ de $575 \mu \mathrm{L}$ de antiveneno/mg de veneno.

La necropsia de todos los ratones utilizados mostró hemorragia intraperitoneal con excepción de los controles negativos. 


\section{DISCUSIÓN}

Warr et al., (18) informaron que los anticuerpos de gallina muestran propiedades precipitantes solo en altas concentraciones de sal, con un valor óptimo de 1,5 $\mathrm{M}$ de $\mathrm{NaCl}$. Es así que Mc Laren et al. (15) describieron anticuerpos $\lg Y$ precipitantes para $\alpha$-lactoalbúmina $(14,4 \mathrm{kDa})$, de la misma manera, Kumar y Gowda ${ }^{(6)}$, en fracciones toxicas de bajo peso molecular del veneno de Daboia russelii. En este aspecto la técnica de inmunodifusión doble fue exitosa para evidenciar bandas de bajo peso molecular, especialmente en venenos procedentes de la India.

Al ser la ponzoña de $B$. atrox del Perú, una mezcla de proteínas principalmente en el ámbito de $55 \mathrm{kDa}$ $11 \mathrm{kDa}{ }^{(19)}$ es posible que se formen complejos precipitables con $\mathrm{NaCl} 1 \mathrm{M}$. La conformación molecular de la lgY es responsable de este fenómeno; los brazos de unión al antígeno (Fab) podrían adquirir independencia funcional, es decir, flexibilidad una de la otra, permitiendo el entrecruzamiento con los epítopes de dos antígenos $(\mathrm{Ag})$ en el veneno completo. Según nuestros resultados, el método de inmunodifusión doble puede ser utilizado para evaluar la presencia de anticuerpos IgY reactivos al Ag de B. atrox tanto con suero como con extractos de yema.

El método de dilución acuosa, desarrollado por Akita y Nakai ${ }^{(20)}$, es el más simple y rápido para el aislamiento de IgY de la yema, pero permite el coaislamiento de varios contaminantes que reducirían la reactividad del antiveneno. Almeida et al. ${ }^{(5)}$, combinaron la precipitación positiva del sulfato de sodio y la precipitación negativa usando ácido caprílico y concluyeron que el método logra anticuerpos mejor aislados y un antiveneno más eficiente. En el presente trabajo se ha adaptado el método de Mc Laren ${ }^{(15)}$, que combina el tratamiento con ácido caprílico de la yema diluida y la posterior precipitación con sulfato de amonio, con lo que se obtiene toda la masa de anticuerpos con pocas proteínas contaminantes (Figura 1). Los ajustes experimentales llevados a cabo ${ }^{(21,22)}$ fueron confirmadas como óptimos y necesarias por Araujo et al. (2) en un estudio sobre el desarrollo del proceso del antiveneno botrópico basado en IgY. Con este procedimiento se logró obtener una concentración proteica de $8,5 \pm 1,35 \mathrm{mg} /$ $\mathrm{mL}$ de yema, en concordancia con lo descrito por Ruan et al. ${ }^{(23)}$ quienes usaron la misma técnica de aislamiento y obtuvieron $9 \pm 2 \mathrm{mg} / \mathrm{mL}$; asimismo, obtuvimos $127,5 \mathrm{mg}$ por yema total, lo que está en el intervalo de 100 a $250 \mathrm{mg}$ establecido en estudios previos ${ }^{(15,5)}$.

Por otro lado, el título alcanzado fue de 12800 a partir de la octava semana de iniciado el protocolo de inmunización, estos valores son similares tanto en el suero como en la yema aviares. Asimismo, se observa la rápida aparición de anticuerpos a las dos semanas cuando es inyectado un refuerzo, respuesta que puede explicarse debido a la presencia de células $B$ de memoria producidas en las gallinas inmunizadas (Figura 2). Almeida et al. ${ }^{(5)}$ informaron títulos similares en los antivenenos IgY contra los géneros Bothrops y Crotalus, valores que se mantuvieron hasta 24 semanas. Los antivenenos IgY producidos por Meenatchisundaram et al. contra los venenos de las especies asiáticas Naja naja y Bungarus caeruleus tuvieron títulos mayores a 10000 hasta por 180 días ${ }^{(8)}$. En el presente trabajo, el precipitado obtenido fue resuspendido en el mismo volumen inicial de yema extraída $(10 \mathrm{~mL})$ para así comparar los niveles de anticuerpos tanto en suero como en extractos de yema (Figura 2). Según Van Dong et al. ${ }^{(24)}$, puede considerarse un título alto para antivenenos sobre el valor de 32000 , esto es casi tres veces más alto que el determinado en el presente trabajo; sin embargo, se debe considerar la concentración proteica de un antiveneno equino, el cual oscila entre $51-105 \mathrm{mg} / \mathrm{mL}$ para liofilizados o líquidos respectivamente ${ }^{(25,26)}$.

Nuestros resultados indican que el veneno de $B$. atrox es un buen inmunógeno, a juzgar por el porcentaje conseguido de anticuerpos IgY específicos purificados y detectados en este trabajo, cuyos valores fueron: $8,3 \%$ utilizando cromatografía de afinidad cuantitativa ${ }^{(4)}$ y $6 \%$ por ELISA.

Sobre el uso de lgY como herramienta inmunoanalítica en la caracterización de venenos, existe aún escasa información, estando las publicaciones en su mayoría orientadas a ensayos de neutralización de actividades biológicas de venenos. Los resultados de esta investigación muestran la reacción cruzada entre los venenos de $B$. atrox y especies del mismo género, determinado por ELISA, siendo el veneno de $B$. brazili el que presentó un mayor porcentaje $(46 \%)$, resultado que indicaría la presencia de un mayor número de determinantes antigénicos compartidos por los componentes de ambos venenos, la presencia de una banda altamente reactiva (revelada por Western blot) de $37 \mathrm{kDa}$ en el veneno de $B$. brazili sería responsable de este porcentaje. En el ámbito de bajo peso molecular el veneno de $B$. pictus muestra dos bandas reactivas de aproximadamente $\sim 20 \mathrm{kDa}$ y $\sim 14 \mathrm{kDa}$ cuyos pesos se encuentran en la región donde se ubican las fosfolipasas del tipo $A_{2}$ en los venenos botrópicos ${ }^{(27)}$; por otro lado, el veneno de $B$. barnetti no presentó bandas reactivas en esta región donde sí son observadas bandas teñidas dentro de su perfil electroforético, indicando que dichas proteínas no comparten epítopes antigénicos.

Se ha demostrado por Western blot que las IgY reconocen predominantemente bandas proteicas de bajo peso 
molecular (10-20 y $20-29 \mathrm{kDa})^{(11)}$, en cambio las IgG reconocen de preferencia proteínas de alto peso molecular (entre 46 y $77 \mathrm{kDa}$ ). En nuestro trabajo, la banda obtenida por la crotoxina de $C$. durissus con IgY en este trabajo, es más densa y notoria que la registrada cuando se emplea IgG anti-B.atrox producida en conejos ${ }^{(28)}$, lo que indicaría un mejor reconocimiento de epítopes sobre crotoxina con las IgY en estudio. En resumen, las IgY reconocen un menor número de bandas de reactividad cruzada que las descritas para IgG de conejos por Western blot pero por ELISA la señal de reconocimiento de epítopes comunes fue mayor. Estos datos evidencian la ventaja de utilizar gallinas las cuales proveen un repertorio nuevo de anticuerpos útiles, abundantes y baratos.

La $\mathrm{DL}_{50}$ determinada en el presente trabajo $(3,3 \pm 0,5 \mu \mathrm{g} / \mathrm{g}$ de ratón) está en el intervalo de 58-100 $\mu \mathrm{g}$ /ratón descrito por Segura A. et al. (29) mostrando que el veneno utilizado es un referente de buena potencia.

La neutralización de la actividad letal de este veneno fue ensayada usando razones de 1000,500 y $250 \mu \mathrm{L}$ de antiveneno/veneno. Se demostró la eficiencia del antiveneno $\mathrm{lg} Y$ a concentración de $35 \mathrm{mg} / \mathrm{mL}$, con una $\mathrm{DE}_{50}$ de $575 \mu \mathrm{L}$ de antiveneno/mg de veneno. Es importante mencionar la cantidad en miligramos de proteína de antivenenos aviares y equinos para fines comparativos $y$ debe considerarse también que la efectividad o potencia de un antiveneno es influenciada por algunos factores como la pureza de las inmunoglobulinas aisladas y los métodos utilizados para su obtención.

Dentro de los estudios preclínicos de antivenenos descritos en los últimos años, el antiveneno preparado de origen aviar tiene una efectividad comparable con la $D E_{50}$ determinada para el antiveneno botrópico producido por el INS de Perú: $127 \pm 67 \mu \mathrm{L}$ de antiveneno/ $\mathrm{mg}$ de veneno utilizando una dosis reto de $4 \mathrm{DL}_{50}{ }^{(29)}$.

En comparación con los resultados obtenidos para antivenenos botrópicos de origen aviar, Almeida et al. (5) obtuvieron valores de $\mathrm{DE}_{50}$ de $592,5 \mu \mathrm{L} / 2 \mathrm{LD}_{50}$ utilizando una mezcla de venenos botrópicos, dichos valores fueron menores en relación a los obtenidos en el presente trabajo.

Una de las características del antiveneno aviar es que permite ajustar su concentración aumentando así su potencia, es decir, la cantidad de veneno neutralizado por cada mililitro de antiveneno. Según la WHO, en su guía de antivenenos de serpiente, la concentración proteica no debe exceder los $100 \mathrm{mg} / \mathrm{mL}$, de esta manera garantizamos que el antiveneno aviar preparado este dentro de una concentración normal de contenido proteico, queda por resolver aún la concentración crítica de un antiveneno aviar debido a la solubilidad del anticuerpo $\lg Y$.
Araujo et al. (2) produjeron un antiveneno botrópico contra venenos de cinco especies brasileñas, logrando que el antiveneno lgY tenga una concentración proteica de $2,57 \mathrm{mg} / \mathrm{mL}$ de yema con una $D E_{50}$ de $365 \mu \mathrm{L} / 2 \mathrm{LD}_{50}$. Hay que mencionar que en la producción de antivenenos equinos de la región brasileña se utilizan mezclas de venenos botrópicos que no incluyen $B$. atrox debido a que la reactividad cruzada de la mezcla con este veneno es utilizada para neutralizar su actividad letal, por lo tanto, estos valores de comparación relativos son importantes porque nos dan un indicio de la calidad del antiveneno aviar producido.

El estudio tiene limitaciones. En la elaboración de antivenenos utilizando la tecnología IgY son necesarios estudios utilizando otros venenos de serpientes peruanas para generar más evidencia científica que garantice la eficacia in vivo de este tipo de inmunoglobulinas, así como se requiere estudios relacionados con su inocuidad. Los protocolos de inmunización con venenos de serpiente deben considerar el efecto sobre el rendimiento en la postura ya que influye drásticamente sobre la relación costo/beneficio. Además, esta investigación es un modelo experimental, por lo que la eficacia neutralizante en humanos necesita un diseño distinto para ser confirmada.

En conclusión, se ha obtenido IgY purificada contra el veneno de $B$. atrox con capacidad neutralizante y se ha demostrado su utilidad como herramienta inmunoanalítica para evaluar la reactividad cruzada con venenos de otras especies. Podemos señalar que gracias a la tecnología lgY desarrollada para la presente investigación, se pueden preparar anticuerpos IgY que pueden ser potencialmente empleados como antivenenos luego de la evaluación que establecen las normas internacionales.

\section{Contribuciones de autoría}

JM participó en la concepción y diseño del trabajo, recolección y obtención de resultados, análisis e interpretación de datos y redacción del manuscrito. DV participó en la recolección y obtención de resultados, análisis e interpretación de datos y revisión crítica del manuscrito. ER participó en la revisión crítica del manuscrito, aprobación de su versión final y asesoría técnica. RI participó en la recolección y obtención de resultados, análisis e interpretación de datos y revisión crítica del manuscrito. GS participó en el análisis e interpretación de datos, redacción del manuscrito y asesoría técnica. FL participó en el análisis e interpretación de datos, revisión crítica del manuscrito y asesoría técnica o administrativa. AY participó en la concepción y diseño del trabajo, análisis e interpretación de datos, revisión crítica del manuscrito, aprobación de su versión final y obtención de financiamiento.

\section{Fuentes de financiamiento}

Estudio financiado por el Vicerrectorado de Investigación de la Universidad Nacional Mayor de San Marcos. 


\section{Conflictos de interés}

Los autores declaran no tener conflictos de interés en la publicación de este artículo.

\section{REFERENCIAS BIBLIOGRÁFICAS}

1. Loja D, Aviles R, Necochea Y, Vilca M, Castro J. Ofidismo por Bothrops atrox: estúdio clínico-epidemiológico Diagnóstico. 2000;39(5):261-5.

2. Araújo AS, Lobato ZI, Chávez-Olórtegui C, Velarde DT. Brazilian IgY-Bothrops antivenom: Studies on the development of a process in chicken egg yolk. Toxicon. 2010;55(4):739-44.

3. Zhang WW. The use of gene-specific lgY antibodies for drug target discovery. Drug Discovery Today. 2003;8(8):364-71.

4. Thalley BS, Carroll SB. Rattlesnake and scorpion antivenoms from the egg yolks of immunized hens. Biotechnology (N Y). 1990;8(10):934-8.

5. Almeida CM, Kanashiro MM, Rangel Filho FB, Mata MF, Kipnis TL, da Silva WD. Development of snake antivenom antibodies in chickens and their purification from yolk. Vet Rec. 1998;143(21):579-84.

6. Kumar AV, Growda TV. Novel non-enzymatic toxic peptide of Daboia russelii (Eastern region) venom renders commercial polyvalent antivenom ineffective. Toxicon. 2006;47(4):398408.

7. Paul K, Manjula J, Deepa EP, Selvanayagam ZE, Ganesh KA, Subba Rao PV. Anti-Echis carinatus venom antibodies from chicken egg yolk: isolation, purification and neutralization efficacy. Toxicon. 2007;50(7):893-900.

8. Meenatchisundaram S, Parameswari $G$, Michael $A$, Ramalingam S. Neutralization of the pharmacological effects of Cobra and Krait venoms by chicken egg yolk antibodies. Toxicon. 2008;52(2):221-7.

9. de Almeida CM, da Silva CL, Couto HP, Escocard Rde C, da Rocha DG, Sentinelli Lde P, et al. Development of process to produce polyvalent lgY antibodies anti-African snake venom. Toxicon. 2008;52(2):293-301.

10. Maya Devi C, Vasantha Bai M, Krishnan LK. Development of viper-venom antibodies in chicken egg yolk and assay of their antigen binding capacity. Toxicon. 2002;40(7):857-61.

11. Brunda G, Sashidhar RB, Sarin RK. Use of egg yolk antibody ( $(\mathrm{gY})$ as an immunoanalytical tool in the detection of Indian cobra (Naja naja naja) venom in biological samples of forensic origin. Toxicon. 2006;48(2):183-94.

12. Finney DJ. Probits Analysis. Cambridge: Cambridge University Press; 1971.

13. Laemmli UK. Clevage of structural proteins during the assembly of the head of bacteriophage T4. Nature. 1970;227(5259):680-5.

14. Warburg $\mathrm{O}$, Christian W. Isrdienmg und Kristallisation des Giirungsfermerrts Enolase (Isolation and crystallization of the enzyme enolase). Biochem Z. 1941;310:384-421.

15. Lowry $\mathrm{OH}$, Rosebrough NJ, Farr AL, Randall R. Protein measurement with the folin phenol reagent. J Biol Chem. 1951;193(1):265-75

16. McLaren RD, Prosser CG, Grieve RC, Borissenko M. The use of caprylic acid for the extraction of the immunoglobulin fraction from egg yolk of chickens immunized with ovine alphalactalbumin. J Immunol Methods. 1994;177(1-2):175-84.
17. Ouchterlony $\mathrm{O}$, Nilsson LA. Immunodiffusion and immunoelectrophoresis. En: Weir DM, Herzerberg LA, Blackwell C, Herzerberg LA, editors. Handbook of Experimental Immunology. 4th ed. Oxford, UK: Blackwell Science Inc; 1986. p. 32.1-32.50.

18. Warr GW, Magor KE, Higgins DA. IgY: clues to the origins of modern antibodies. Immunol Today. 1995;16(8):392-8.

19. Mendoza J, Vivas D, Inga R, Arbaiza E, Rodríguez E, Yarlequé A. Patrones electroforéticos de los venenos de serpientes peruanas de los géneros Bothrops y Lachesis. Rev Soc Quím Perú. 2009;75(2):235-42.

20. Akita E, Nakai S. Immunoglobulins form egg yolk isolation and purification. J Foof Sci. 1992;57(3):629-34.

21. Mendoza J, Sandoval G, Vivas D, Inga R, Severino R, Yarlequé $A$, et al. Obtención y purificación de lgY aviares contra el veneno de Bothrops atrox por cromatografía de afinidad. En: Libro de Resúmenes del XVIII Reunión Científica del ICBAR. Lima, Perú. Instituto de Investigación de Ciencias Biológicas "Antonio Raymondi", Facultad de Ciencias Biológicas de la Universidad Nacional Mayor de San Marcos. 2009. p. T17.

22. Chávez E, Mendoza J, Martínez E, Bonilla-Ferreyra C, Ale N, Yarlequé A. Producción de anticuerpos policlonales IgY contra la bacteria cariogénica Streptococcus mutans. En: Libro de Resúmenes del XVIII Reunión Científica del ICBAR. Lima, Perú. Instituto de Investigación de Ciencias Biológicas "Antonio Raymondi", Facultad de Ciencias Biológicas de la Universidad Nacional Mayor de San Marcos. 2009. p. T17.

23. Ruan GP, Ma L, Meng XJ, Meng MJ, Wang XN, Lin Y, et al. Quantification of antibody $(\lg Y)$ titers in hen eggs following immunization and their use in detecting cell surface molecules on nitrocellulose membranes. J Immunoassay Immunochem. 2007;28(1):35-45

24. Van Dong L, Quyen Le K, Eng KH, Gopalakrishnakone P. Immunogenicity of venoms from four common snakes in the South of Vietnam and development of ELISA kit for venom detection. J Immunol Methods. 2003;282(1-2):13-31.

25. García P, Yarlequé A, Bonilla-Ferreyra C, Pessah S, Vivas D, Sandoval G, et al. Características bioquímicas y evaluación preclínica de un antiveneno botrópico liofilizado contra el veneno de la serpiente Bothrops atrox. Rev Peru Med Exp Salud Publica. 2008;25(4):386-90.

26. Yarlequé A, Vivas D, Inga R, Rodríguez E, Sandoval G, Pessah S, et al. Acción del antiveneno botrópico polivalente sobre las actividades proteolíticas presentes en los venenos de serpientes peruanas. Rev Peru Med Exp Salud Publica. 2008;25(2):169-73.

27. TuA. Phospholipases $A$. En:Venoms: Chemistry and molecular biology. Hoboken, NJ: Edit Wiley-Interscience; 1977.

28. Sandoval G. Inmunogenicidad del veneno de Bothrops atrox (Ophidia: Viperidae) y su evaluación por métodos inmunoenzimáticos. Rev peru biol. 2011;18(3):335-41.

29. Segura A, Castillo MC, Núñez V, Yarlequé A, Gonçalves LR, Villalta M. et al. Preclinical assessment of the neutralizing capacity of antivenoms produced in six Latin American countries against medically-relevant Bothrops snake venoms. Toxicon. 2010;56(6):980-9.

Correspondencia: Julio César Mendoza Fernández

Dirección: Mz H. Lote 16 Grupo 23 Sector I. Lima 42, Perú.

Teléfono: (51) 987743796

Correo electrónico: sfexryu@gmail.com 